\title{
L'exercice de l'autorité dans le chiisme duodécimain contemporain : doctrines et institutions
}

Doctorat d'histoire, sous la direction de Christian Décobert, École des hautes études en sciences sociales (EHESS), soutenu le 15 septembre 2011.

\section{Constance Arminjon}

\section{CpenEdition} Journals

\section{Édition électronique}

URL : https://journals.openedition.org/assr/24576

DOI : $10.4000 /$ assr.24576

ISSN : $1777-5825$

Éditeur

Éditions de l'EHESS

Édition imprimée

Date de publication : 30 décembre 2012

Pagination : 309-358

ISSN : 0335-5985

\section{Référence électronique}

Constance Arminjon, «L'exercice de l'autorité dans le chiisme duodécimain contemporain : doctrines et institutions ", Archives de sciences sociales des religions [En ligne], 160 | octobre-décembre 2012, mis en ligne le 30 décembre 2012, consulté le 28 juin 2022. URL : http://journals.openedition.org/assr/ 24576 ; DOI : https://doi.org/10.4000/assr.24576 


\section{L'exercice de l'autorité dans le chiisme duodécimain contemporain: doctrines et institutions}

Doctorat d'histoire, sous la direction de Christian Décobert, École des hautes études en sciences sociales (EHESS), soutenu le 15 septembre 2011.

\section{Constance Arminjon}

1 En identifiant la fonction du juriste religieux à l'autorité du Prophète, l'ayatollah Khomaynî voulut combler les brèches survenues dans la transmission du modèle d'autorité idéal de l'islam. Érigé en représentant du dernier Imâm (art. 5 de la Constitution iranienne de 1979), le valî-e faqîh - le juriste religieux détenteur de l'autorité, velâyat tendit à abolir le temps et les obstacles historiques et théologiques de la tradition des Imâms. Alors qu'il cristallisait ainsi une utopie, il contribua à enraciner le chiisme dans la modernité politique. Quoiqu'il définît l'autorité de gouvernance en termes religieux, le Guide de la République islamique œuvra à une autonomisation du juriste à l'égard de la loi religieuse elle-même en proclamant le primat du politique dans l'islam et en dépassant la distinction théologique entre le Prophète et les Imâms d'une part, et le juriste faillible de l'autre.

2 À l'encontre d'une visée messianique, la plupart des autorités religieuses («sources d'imitation »- marjac) chiites firent valoir cette distinction pour récuser l'unification des instances. Elles s'inscrivaient dans une autre lignée d'autorité, qui connut une rupture à leurs yeux irréversible lors de l'Occultation du dernier Imâm. La pérennisation de l'État islamique iranien et la persistance de l'institution de l'autorité religieuse (marjaciyya) ont finalement consacré la reconfiguration des rapports entre deux ordres irréductibles d'autorité. À la suite de la révision constitutionnelle de 1989, le Guide de la République islamique d'Iran - qui incarne l'institution de la velâyat-e faqîh, la " guidance du juriste » exerce une gouvernance à finalité religieuse. Dans le même temps, les marjac perpétuent une fonction de guidance pour les individus comme pour la communauté chiite. Les deux 
institutions actualisent ipso facto au sein même du champ clérical chiite la bipolarité de l'autorité religieuse, structurelle dans le chiisme et sans doute plus généralement dans l'islam. Par-delà les tensions inhérentes aux rapports entre deux ordres, la velâyat-e faqîh et la marjaciyya attestent ainsi de la division du travail religieux. Dans le même temps, la polarisation opère au sein de chacune d'elle. Le modèle de la double autorité assumée par le fondateur de la République islamique exerce un attrait sur certains marjac , de sorte que la marjaciyya elle-même est polarisée entre deux paradigmes. Réciproquement, bien qu'il affirme la primauté de la gouvernance dans l'islam, le Guide iranien actuel cAlî Khâmeneh'î exerce de fait une double fonction.

3 Tout en invoquant une commune histoire, les représentants des deux lignées manifestent la plurivocité en même temps que le perpétuel dynamisme de la tradition. Au prisme de deux paradigmes fondateurs et inassimilables, ils procèdent à des lectures divergentes de leur héritage pour s'ancrer dans la modernité. L'élaboration de la modernité est par conséquent aussi polyphonique que la tradition, laquelle est continuellement reformulée. Les échos suscités par Khomaynî de son vivant comme après sa mort illustrent une forme de dialogue de la tradition avec elle-même. Ce dialogue met certes au jour le pluralisme existant au sein du clergé chiite, mais aussi une profonde communauté de vues sur certains principes fondamentaux comme le lien entre religion et politique et l'attachement à la Communauté. De même l'ensemble des clercs tient à préserver les institutions. En outre, le pluralisme des voies s'est illustré autant dans l'essor des théories politiques que dans le fonctionnement des institutions d'autorité.

Conçue d'abord comme un remède à la sécularisation de la société, la velâyat-e faqîh assume une fonction de gouvernance dont le caractère religieux consiste essentiellement dans la finalité et le statut du détenteur de l'autorité. Sans contenu spécifique, la velâyat-e faqîh peut ainsi s'intégrer dans la modernité politique. En institutionnalisant une révolution théologique, la fondation de la République islamique donna ainsi aux clercs les moyens de ne plus être les témoins passifs d'une modernité perçue comme exogène. L'équivalence posée entre « loi islamique » et loi du gouvernement islamique, qui a soustendu l'élaboration du droit dans la République islamique, permet potentiellement la modernisation de l'ensemble du droit.

$5 \quad$ S'ils arguent de leur fidélité aux enseignements des Imâms pour récuser la métamorphose du juriste religieux, les marja ${ }^{c}$ ne sont pas pour autant les témoins d'une tradition immuable. En premier lieu, en perpétuant un mode pluraliste et informel d'exercice de l'autorité sans pouvoir contraignant, de même qu'en renouvelant les modalités de leurs relations avec les fidèles, ils témoignent de leur attachement à un fondement de l'institution du clergé chiite autant que de leur capacité d'adaptation à une religiosité moderne souvent rétive à l'institutionnalisation systématique de l'autorité. La forte personnalisation de l'autorité peut se révéler également adéquate aux pratiques religieuses modernes, marquées par une forte tendance à l'individualisation. En second lieu, tout en exprimant leur fidélité à une ligne doctrinale, les marja ${ }^{c}$ ont su conserver une influence parfois décisive dans le champ sociopolitique. En exerçant une fonction de guidance pour l'ensemble de la Communauté, ils peuvent à leur tour collaborer à l'émergence d'un autre modèle de modernité politique, qui est susceptible de stimuler à son tour un nouvel essor théorique. De fait, sans se départir d'une posture « traditionnelle » de guidance et sans remettre en question l'organisation de la marjaciyya, l'ayatollah Sîstânî est une autorité tutélaire dans la refondation de l'État iraquien. 
6 Les transformations institutionnelles et l'essor des doctrines engendrés par l'instauration d'un État clérical en Iran ont confirmé le rôle structurant de l'État dans l'organisation de l'autorité religieuse chiite. Dans le même temps, la reconfiguration du champ religieux a mis en évidence la constante dialectique entre les deux instances. En effet, la polarisation de la marjaciyya et le contrôle d'une partie du clergé iranien ont révélé l'attraction et l'emprise de l'État sur le champ religieux. Inversement, la résilience de la marjaciyya aux contraintes étatiques prouve le caractère inaliénable d'un mode spécifique d'autorité.

7 Tandis que la reconstruction des institutions étatiques iraquiennes représente un nouveau laboratoire pour la modernité politique dans le chiisme, plusieurs courants intellectuels en Iran tendent à un profond renouvellement du champ de l'autorité par une ouverture de la pensée religieuse. Ainsi, malgré leur cohésion interne et leur capacité à se transformer, les institutions d'autorité chiites sont l'objet de mises en question aiguës non seulement par des intellectuels laïcs, mais également par des clercs. Depuis une vingtaine d'années, l'élan qui incite intellectuels laïcs et clercs iraniens à redéfinir la fonction des institutions d'autorité et plus largement celle de la religion dans la société procède de plusieurs crises dont les effets sont convergents. Ces crises affectent la religiosité traditionnelle, l'institution cléricale, l'idéologie islamique révolutionnaire, l'État clérical, le modernisme. Elles s'inscrivent en outre dans le contexte plus large de la sécularisation de la société et de la mondialisation. À la mesure de tels bouleversements sociaux, politiques et institutionnels, les réponses sont à la fois amples et diversifiées.

Quoique laïcs et clercs participent simultanément au renouvellement de la pensée de l'autorité, leur différence de statut a des répercussions tant sur leurs projets que sur leurs méthodes et sur la portée de leurs positions. Il convient cependant de clarifier les confluences entre les intellectuels laïcs et clercs, d'autant plus que les idées des premiers sont largement discutées dans les milieux cléricaux. Plusieurs courants et tendances doivent donc être distingués. Parmi les intellectuels laïcs, deux courants coexistent depuis le début des années 1990. Le premier, symbolisé par ${ }^{\mathrm{c} A b d}$ ol-Karîm Sorûsh, tente de définir un islam désidéologisé et libéral. Le second, d'inspiration spiritualiste, s'attache surtout à redéfinir la religion elle-même. Même s'ils s'interpénètrent, ils ont des finalités différenciées. Parmi les clercs, deux principales tendances se distinguent, qui peuvent coexister chez certains individus. Tout d'abord, certains adoptent une approche essentiellement critique des institutions dans le strict cadre du droit islamique : le cheikh Mohsen Kadivar est le représentant le plus marquant de cet effort. D'autres clercs s'attachent à établir un bilan des institutions d'autorité et de leurs rapports, tout en exprimant des conceptions politiques positives. Les plus éminents témoins de cette tendance sont Hasan Yûsofî Eshkevârî et l'ayatollah Montazerî. Après avoir contribué de manière décisive à institutionnaliser la "guidance du juriste» en Iran, le second envisagea dans les dernières années de sa vie les modalités d'une démocratie religieuse.

Il est bien trop tôt pour prévoir les conséquences des critiques et propositions de réforme formulées par le troisième courant de clercs, pour reprendre l'expression de l'un d'entre eux, Hasan Yûsofî Eshkevârî. L'élargissement du champ d'appréhension de la religion et de sa fonction apparait toutefois indéniable. Ainsi, outre les systèmes d'autorité, l'islam lui-même est l'objet de constants questionnements et redéfinitions. 


\section{AUTEUR}

CONSTANCE ARMINJON

constancearminjon@yahoo.fr 